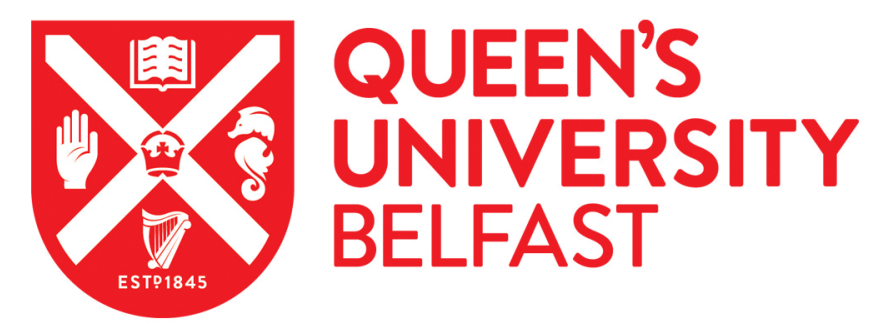

\title{
Collaborative learning in architectural education: Benefits of combining conventional studio, virtual design studio and live projects
}

Rodriguez, C., Hudson, R., \& Niblock, C. (2018). Collaborative learning in architectural education: Benefits of combining conventional studio, virtual design studio and live projects. British Journal of Educational Technology, 49(3), 337-353. https://doi.org/10.1111/bjet.12535

Published in:

British Journal of Educational Technology

Document Version:

Peer reviewed version

Queen's University Belfast - Research Portal:

Link to publication record in Queen's University Belfast Research Portal

Publisher rights

(c) 2016 British Educational Research Association. This work is made available online in accordance with the publisher's policies. Please refer to any applicable terms of use of the publisher.

\section{General rights}

Copyright for the publications made accessible via the Queen's University Belfast Research Portal is retained by the author(s) and / or other copyright owners and it is a condition of accessing these publications that users recognise and abide by the legal requirements associated with these rights.

Take down policy

The Research Portal is Queen's institutional repository that provides access to Queen's research output. Every effort has been made to ensure that content in the Research Portal does not infringe any person's rights, or applicable UK laws. If you discover content in the Research Portal that you believe breaches copyright or violates any law, please contact openaccess@qub.ac.uk. 
Collaborative Learning in Architectural Education: Benefits of Combining Conventional

Studio, Virtual Design Studio (VDS) and Live Projects

\author{
Carolina Rodriguez, Roland Hudson and Chantelle Niblock
}

Dr. Carolina M. Rodriguez is an architect from Universidad Nacional de Colombia with a PhD from NottinghamUniversity, UK and more than 16 years of experience in teaching, research and academic administration atuniversity level. She has worked as a lecturer at The University of Los Andes in Colombia, The University of Nottingham and The University of Liverpool in England. In these positions, Carolina has established a track record of high quality publications and research grants. She has specialised in designing pedagogical methods and active teaching and learning strategies. Dr. Roland Hudson is a part-time Professor in the Department of Architecture at the University of Los Andes and an independent researcher and consultant applying computational design in architecture. Dr. Chantelle Niblock is a Lecturer in Architecture and Course Director of MArch Digital Architecture and Tectonics at the University of Nottingham. Address for Correspondence: Dr. Carolina M. Rodriguez, Universidad Nacional deColombia, Colombia. Email: cm.rodriguez@uniandes.edu.co

\begin{abstract}
Combinations of Conventional Studio and Virtual Design Studio (VDS) have created valuable learning environments that take advantage of different instruments of communication and interaction. However, past experiences have reported limitations in regards to student engagement and motivation, especially when the studio projects encourage abstraction or are detached from context or reality. This study proposes a hybrid approach that overcomes these limitations by blending conventional studio, VDS and live projects. This blend aims to foster opportunities for collaborative learning within a real design situation, whilst promoting different levels of motivation and engagement. Two case studies comprising academic projects between the University of Los Andes, Colombia and the University of Nottingham, UK were used to validate the approach. Students interacted with peers, teachers, people from industry and the community to build 1:1 scale projects, with budgets and a timeframe constrains. The study proved that students could successfully work collaboratively and build confidence in their own abilities when placed in a real setting, which allowed interactions face-to-face and at a distance to solve a challenge and achieve a
\end{abstract}


common goal. The article reports on lessons learnt from this collaborative learning experience, which reflect on contemporary cross-cultural design practiced today.

Keywords: collaborative learning, distance learning, architectural education, live projects, project-based learning, virtual studio

\section{Practitioner Notes}

What is already known about this topic

- Conventional studio teaching has numerous advantages due to face-to face interactions between students and teachers. However, acquisition of knowledge is centred on personal experiences, which may privilege or benefit only certain individuals. There are also concerns regarding excessive abstraction and disconnection from real design problems.

- Live projects are effective pedagogical strategies to connect the world of academia with the world outside. However, they require great administrative effort and resources.

- Singular learning activities and tools may favour only one particular type of motivational or behavioural engagement.

\section{What this paper adds}

- A hybrid approach that combines conventional studio, VDS and live projects, which results in a novel and effective collaborative learning method in architectural education.

- Innovative learning activities designed to instigate and maintain student engagement and motivation at different levels.

\section{Implications for practice and/or policy}

- The case studies presented here provide new insights into established ways of teaching, which could result in adjustments and improvements to existing curricula. 
- The article includes remarks and recommendations that could help educators when applying the proposed pedagogical approach.

\section{Introduction}

The motivation for this study initially stemmed from awareness of the speed of change in information communication technology (ICT). Depending on the way it is used, this may either help or hinder collaboration between teams of designers in architectural education and in practice. In a review of recent academic research on collaborative architectural design opportunities presented by ICT in practice, two distinct types of applications can be identified. The first relates to the improved performance of existing tools in commercial applications where collaboration focuses on sharing building information models placed in cloud based storage (Singh \& Wang, 2011). The second centres on developing new communication platforms that allow instant model updates or use virtual reality (Ong et al., 2013). There is a common belief that new ICT tools should be the focus to inform better collaboration through the design process, from the initial conceptualisation (Joklová \& Henrich, 2015) to the construction and project management stages (Onyegiri et al., 2011). However, other research indicates that developing better personal relationships may be more important for quality collaborations than acquiring specific ICT tools. For example, Kvan (2000) suggested that in many cases designers are actually co-operating instead of collaborating. He argued that working together, even effectively, is not necessarily collaboration, it might be better defined as an act of co-operation or co-ordination in order to achieve success. In many cases this can be achieved simply by shearing information via ICT tools. Collaboration, on the other hand, is a deeper, more personal synergistic process, which is time consuming and requires relationship building. It is normally suited to very particular 
problems that require a strong connection between participants during the design process. Cooperation could be reached if all participants have assigned parts separately and bring their results together; collaboration, in contrast, implies direct interaction among individuals and involves negotiations, discussions, and accommodating others' perspectives (Kozar, 2010). Kvan (2000) proposes that better collaboration may be achieved when existing ICT tools are more loosely coupled. From this perspective, employing readily available and well-developed tools allows user generated content to play a central role. In particular, if these tools are WEB 2.0 focus; in other words, where users can interact and collaborate with each other, generate content, share information and create virtual networks and communities (social media).

The dynamics generated within architectural practice directly impact the way students are encouraged to work collaboratively within an academic environment (Wang, 2012). University students are some of the earliest adopters of social media and other WEB 2.0 focus tools. Hence, pedagogies such as virtual design studio (VDS) have taken advantage of this to facilitate design collaboration between geographically dislocated teams. The use of these tools has been a theme for discussion over the last two decades in the context of architectural education (Mitchell, 1995; Maher et al., 2000; Harrison \& Donn, 2006; Schnabel and Ham, 2012). Previous studies have shown that collaborative learning experiences with VDS not only promote the development of professional skills in a multicultural society, but also encourage critical thought and enhance the understanding of diversity (Hou et al., 2005). However, a number of limitations are linked to VDS related to a potential decrease in student motivation and engagement, and technical and cultural barriers. There are also important concerns raised in regards to the web-based generation of skills that are, in some cases, more consumer-oriented and less educational (Achten et al., 2011). Search engines and social media websites can induce people to become 'decoders' of 
information, rather than readers with the opportunity to place information within context (Mallgrave, 2010). It has been argued that 'the danger of being detached from physical surroundings is present and should be taken into consideration while design studio is going virtual.' (Achten et al., 2011, p 25). Hence, it is suggested that contemporary VDS should offer something different, such as the introduction of a critical approach to contemporary socio-cultural reality (Achten et al., 2011).

VDS have been coupled in the past with certain elements of conventional studio, since both pedagogies have been found to be complementary (Achten et al., 1999; Livia, 2011; Salama, 2014). In the same vain, conventional studio and pedagogies such as live projects have been used together in other teaching experiences as a way to establish links between the academic environment and the outside community (Harris \& Widder, 2014). This article proposes a novel modification which combines VDS, conventional studio and live projects, in order to promote effective collaborative learning at different levels and via diverse means. This combination aims to complement the qualities and overcome the boundaries that each pedagogy has independently. The article starts by highlighting current opportunities and limitations present in VDS, conventional studio and live projects as isolated teaching methods. Then, it examines benefits of a proposed hybrid approach via two case studies. The case studies involved interactions between University of Los Andes in Colombia, Nottingham University in the UK, and members of other communities in both countries. Participants had the opportunity of working face to face in each country and collaborating at a distance between each other. The article concludes with a summary of the lessons learnt, suggested improvements and potential curricular adjustments.

\section{Pedagogical background}


The principal limitations and opportunities in each of the three pedagogic formats mentioned above are summarised in Figure 1 and further examined in this section.

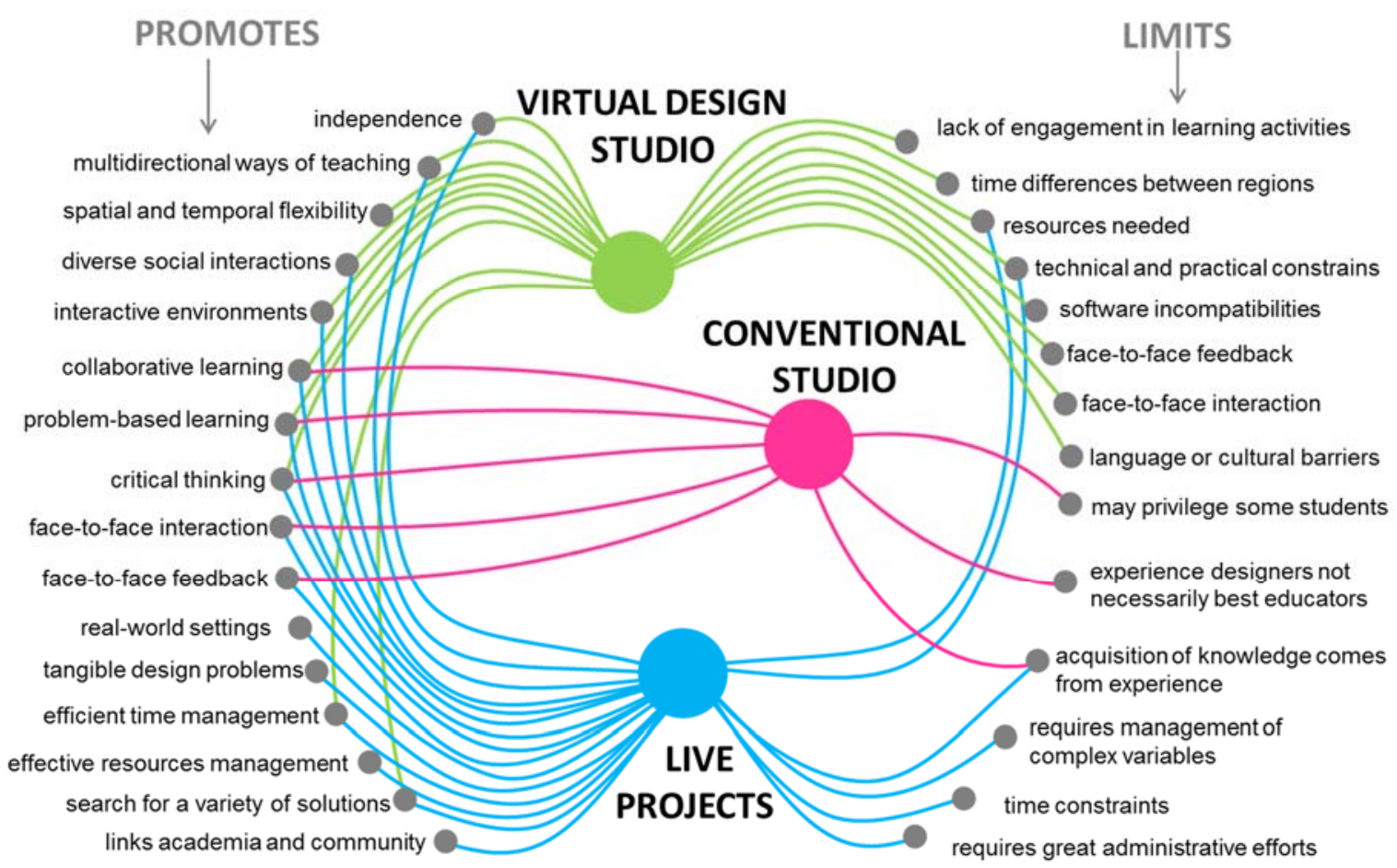

Figure 1: Opportunities and limitations from the use of virtual design studio, conventional studio and life projects in architectural education

\section{Virtual design studio (VDS)}

VDS refers to a format of teaching and learning where participants' communication and collaboration is mediated mainly through asynchronous digital tools, thus overcoming geographical or spatial barriers. These types of tools have been widely used in studentcentred approaches based on constructivist theories (Gül et al., 2012). They allow students to start the class at any time, to study in isolation and to communicate with instructors and classmates using interactive technologies such as video conferencing and social networks like skype and Facebook. In order to enhance and complement the traditional face-to-face and master-apprentice relationships in the conventional studio, from the 1990s numerous schools 
of architecture worldwide have experimented with variations of this format (Achten et al., 1999). Initial explorations often used digital tools mainly for the purposes of e-mail communications and file sharing, and as means of presenting work. As digital technology and global communication systems advance, more sophisticated versions of VDS using computer-aided architectural design, digital prototyping, automated construction methods and WEB 2.0 tools have emerged (Schnabel \& Ham, 2012). The present study mainly focuses on VDS that use WEB 2.0 tools to allow collaboration at a distance, due to their popularity amongst students and their suggested advantages in regards to collaborative work in architecture (Meshur et al., 2014).

It has been suggested that VDS in general can stimulate creativity and empower students to express, explore, and convey their imagination more easily (Schnabel, 2011). The implementation of VDS may generate highly interactive and collaborative studio environments, increasing the sense of community and the interest in social problems (Livia, 2011). It can enrich architectural education by moving away from conventional, linear, and unidirectional ways of teaching. It can also provide an opportunity to create meaningful knowledge, encouraging independence, efficient time management, spatial flexibility, and other types of social interactions that are not feasible in traditional classroom settings (Krämer et al., 2015). However, it is argued that research in this area remains in its infancy and, due to the preconception of the 'unique' nature of traditional, face-to-face studio-based learning, many educators are reluctant to use the VDS format or other asynchronous tools (Meshur et al., 2014). Additionally, very few studies have specifically addressed the role of WEB 2.0 tools in architectural pedagogy (Schnabel and Ham, 2012; Bala \& Arat, 2012). Technical and practical constraints can emerge during the implementation of these types of methods, which include a lack of resources for working with large student groups, software 
incompatibilities, language or cultural barriers between participants or time differences between regions, amongst others (Lavia, 2011). Although this form of distance

communication is appropriate in many cases, there are concerns that students may lack opportunities to interact directly, to actually collaborate, and to receive feedback and social support, all of which could lead to less engagement in learning activities (Tuckman, 2007). There are also concerns related to unresolved issues with students' engagement in the learning process, and their ability to regulate their own learning appears to be critical if they are allowed too much freedom in how and when they interact (Sun \& Rueda, 2012).

\section{Conventional studio}

Conventional studio became increasingly popular in architectural education since the Bauhaus teaching experimentation of the 1930s in Germany (Gül et al., 2012). It has been the centre of architectural education in various countries for many decades, proving to offer numerous advantages, such as the promotion of critical, creative and pragmatic thinking (Lukman et al., 2012). In a common studio-based exercise, students are given a design problem that allows them to direct their own learning through the search for potential solutions. During this process, teachers or experienced practitioners guide the students by questioning their design proposals during face-to-face tutorials and reviews in order to foster critical thought and encourage the search for a variety of solutions. This method has been broadly formalised as 'problem-based' or 'project-based' learning and it is used in many other disciplines (Bridges, 2007). There are countless variations in studio teaching and different ways to structure studio modules within the general curriculum. However, this format has also being criticised because experienced designers are not always the best educators as their operative model for teaching tends to rely on an implicit understanding of how they themselves design (Dooren et al., 2013). Dooren and others argue that some 
teachers resist using specific pedagogies or strategies; hence, the acquisition of knowledge in studio settings is primarily centred on personal experiences. Since there are different types of learners, this approach may privilege only certain individuals. In addition, design studios at all levels are too often insulated from ordinary, everyday life and tend to promote theory without practice (Jarrett, 2000). Jarrett argues that isolating design studio projects from everyday life excludes a world rich in colour, behaviour and circumstances, which may lead to social seclusion and narrow-minded thinking, as well as breed abstraction and detachment from reality. This criticism coincides with concerns regarding VDS pedagogies, highlighted by Achten and others (2011).

\section{Live projects}

Live projects are practical learning experiences that are well established in other fields of education such as business, management, law, health-related disciplines and interactive media (Harris \& Widder, 2014). In architectural education they have been used as alternative means to provide students with real and tangible design problems. Live projects are thought to be effective pedagogical strategies to connect the world of academia with the world outside; although they require larger administrative efforts and more careful time management compared to conventional studio (Anderson \& Priest 2012). There are diverse opinions in terms of their relation with the studio environment. Some educators believe that they are a great complement to other methods in that they reduce the dominance of the studio whilst capitalising on the notion of 'pedagogical events' (Salama, 2014). Others suggest that the nature of the relationship between design studio projects and live projects needs to be revised since both settings facilitate the development of valuable but different abilities and competencies. Design studios can provide an abstracted and risk-free environment for examining concepts in detail and in isolation by stripping away content, conditions, and 
uncontrollable complexities. Life projects, on the other hand, exist in complex, unpredictable circumstances where students need to apply other sets of skills to deliver results under changing conditions. In this context, 'a live project comprises the negotiation of a brief, timescale, budget and product between a client and an educational institution' (Harris \& Widder, 2014, p.xix).

It is argued that in 'live projects' higher levels of motivation are strongly linked to the involvement of real clients and users and the perception that the clients truly valued the work. Students talked about 'making a difference' or a 'lasting effect', and feeling 'proud', knowing that the work was 'going to be used"” (Sara, 2011, p. 13). In contrast, lower levels of motivation and engagement in VDS and conventional studio pedagogies may be linked to the lack of involvement with real clients or problems (Tuckman, 2007; Jarrett, 2000). Previous research suggests that there is a direct link between motivational variables and student engagement in a distance learning setting (Sun \& Rueda, 2012). Motivational variables refer to three main aspects: situational interest, self-efficacy, and self-regulation. These motivational variables are thought to be linked to three types of engagement: behavioural, emotional, and cognitive (see Figure 2 for definitions). These types of engagement have been regarded by Fredricks (2005) as three aspects that, when combined, represent the student's capacity to take ownership of their past, present, and future educational experiences and investment in learning. It has been argued that certain learning activities and tools may favour one particular type of engagement. For example, online multimedia, discussion boards, and distance learning may increase emotional engagement. Likewise, face-to-face tutorials may favour cognitive engagement, and project-based activities may encourage behavioural engagement (Fredricks, 2005). Fredicks theory was taken as framework for this study in order to design and strategic combination of elements 
from the VDS, conventional studio and live project formats, which could potentiate collaborative learning.

\section{The approach}

For the purpose of this work, a deductive methodology was chosen, where a hypothesis was proposed based on the studied pedagogical background and then validated via two case studies (project 1 and project 2). The cases studies were specifically designed to link different learning activities that together would encourage all levels of engagement (Figure 2). These included activities where students had to assume individual responsibility, work with students from other backgrounds, tackle a challenge collectively, resolve a real problem, and/or work in conjunction with the community. The central hypothesis of the two case studies was that students could build confidence in their own abilities through a project that would place them in a real design situation, one where they had the opportunity to work collectively with peers and teachers — face-to-face and at a distance — in order to solve a challenge and achieve a common goal. 


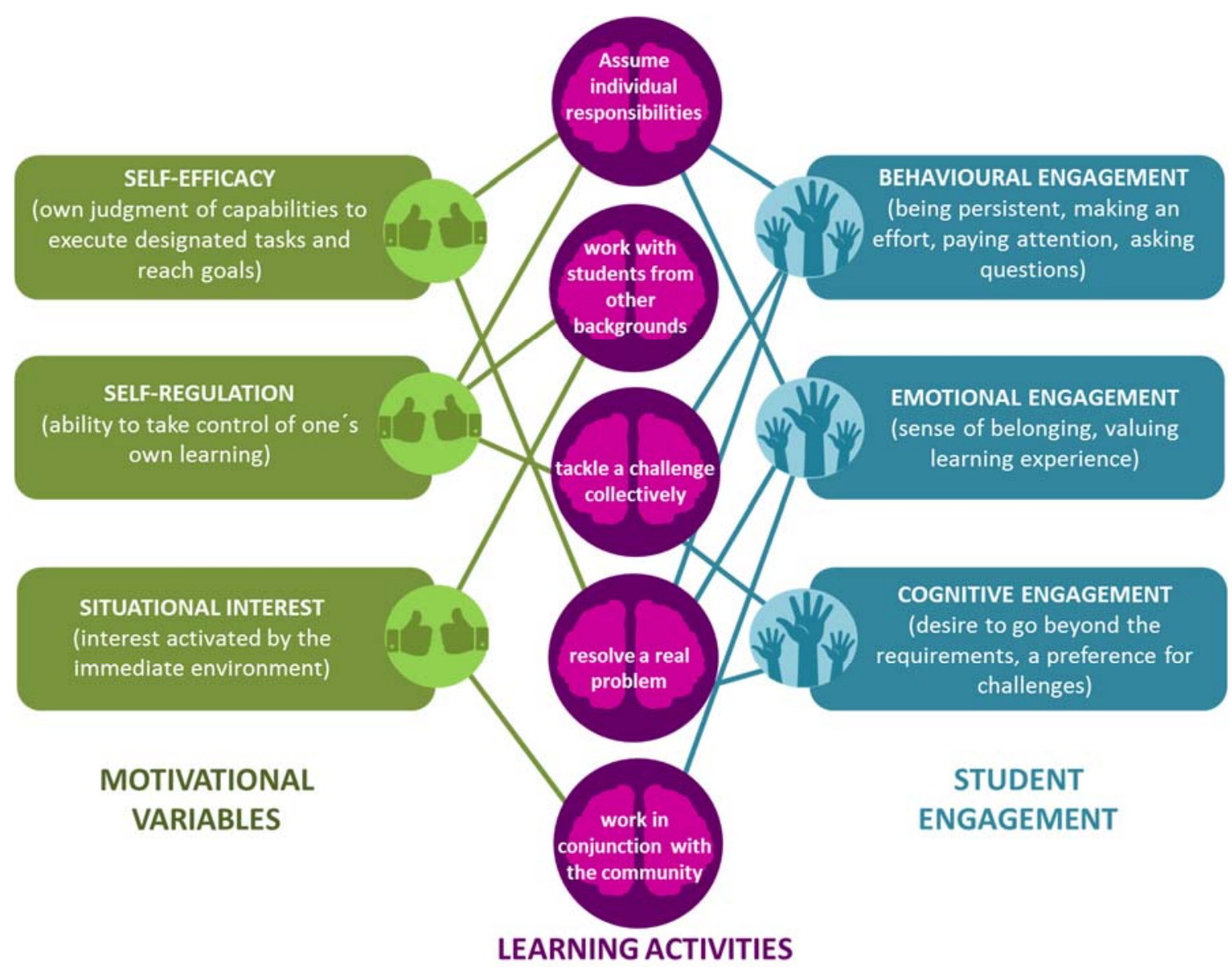

Figure 2: Learning activities designed to foster motivational variables and encourage student engagement

A mixed evaluation method was used to assess students' perceptions of the learning they derived from the projects, which combined triangulation between anonymous online surveys, focus groups with students in each country, and peer review by other teachers. The questions in the surveys were primarily formulated to evaluate motivational variables and student engagement.

\section{The projects}

\section{Project 1: Pavilion in a suitcase}

This ten-week project was centred on a challenge to develop a design proposal for a pavilion, based on the requirements of a brief for the international 2015 IASS Pavilion Contest. One of 
the requirements of the project was that the components of the pavilion could fit into a regular suitcase (within airline's luggage restrictions), hence the name 'pavilion in a suitcase'. The project was carried out in three stages with a group of 25 postgraduate students: 6 from the University of Nottingham, UK, and 19 from the University of Los Andes, Colombia. The first stage entailed a two-week period of conceptual development (VDS format) and this was followed by a two-week proposal development stage (conventional studio format), with a final six-week materialisation stage (live project format) (Figure 3).
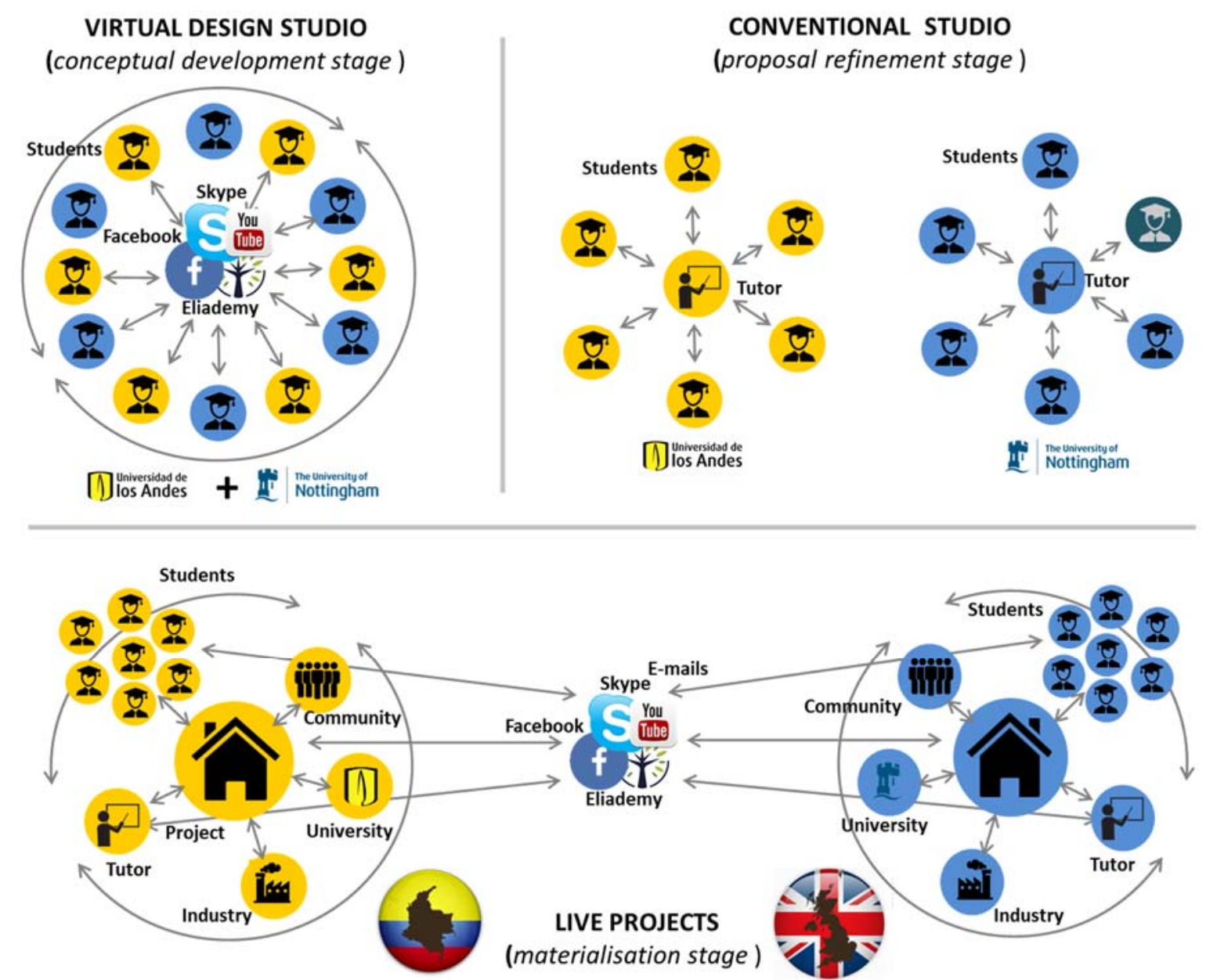

Figure 3: Learning formats used: virtual design studio, conventional studio, and life projects

During the first stage, students from both institutions collaborated to devise a proposal, working in mixed teams of $4-5$ students. At the end of this stage each group 
submitted and shared their proposal via a five-minute video. A panel of judges, formed by lecturers from each university, chose two proposals to develop further. The projects were judged against the same criteria used for international 2015 IASS Pavilion. The aim was to emulate a process of selection characteristic of architecture competitions, where only one or a few projects are chosen from a range of proposals. It was important to communicate to the students that in professional practice initial singular ideas are very often dropped and the team has to work collaboratively in favour of a selected proposal, which is considered to be the best for the project. Students began to understand that the success of the projects is not only based on the selection of this idea, but on the collective performance and relationships built between participants during the design and materialisation process.

Communication between students and teaching staff was possible through an Eliademy webpage used for the online course administration. Additionally, students collaborated through Skype meetings and designated Facebook and Youtube accounts, all of which were used for forums, messaging, and for uploading information (Figure 4). In the course of the second stage, students and teachers worked separately in each country via regular face-to-face tutorials and workshops. Students were encouraged to engage with empirical exploration and research throughout the design process using analogue and digital tools. For the third stage, guest lecturers and experts from both universities and from the industry were consulted in order to enrich and refine the schemes. This period included a prototyping, testing, and construction phase, followed by a final evaluation exercise. 

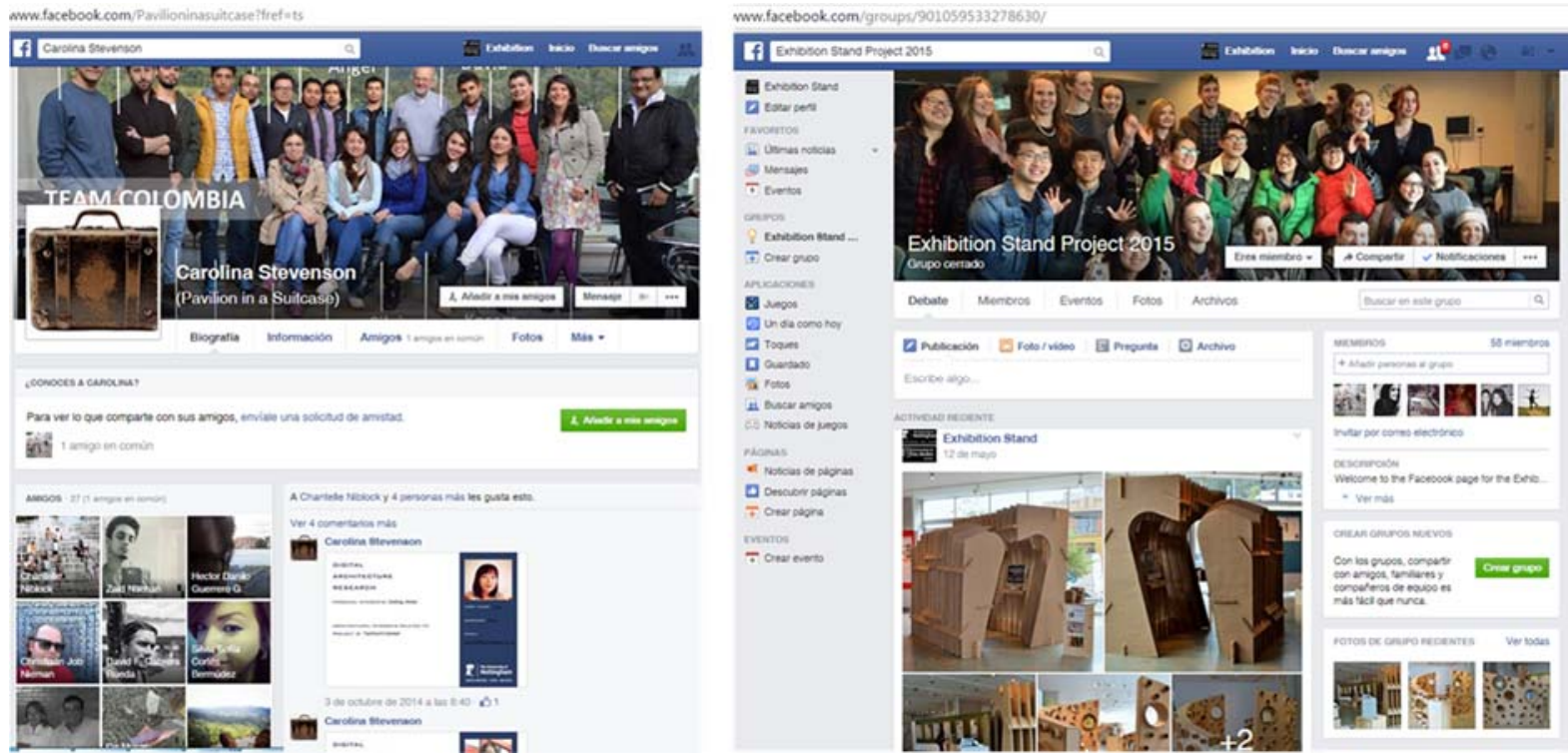

Figure 4: Example of the digital tools used for communication
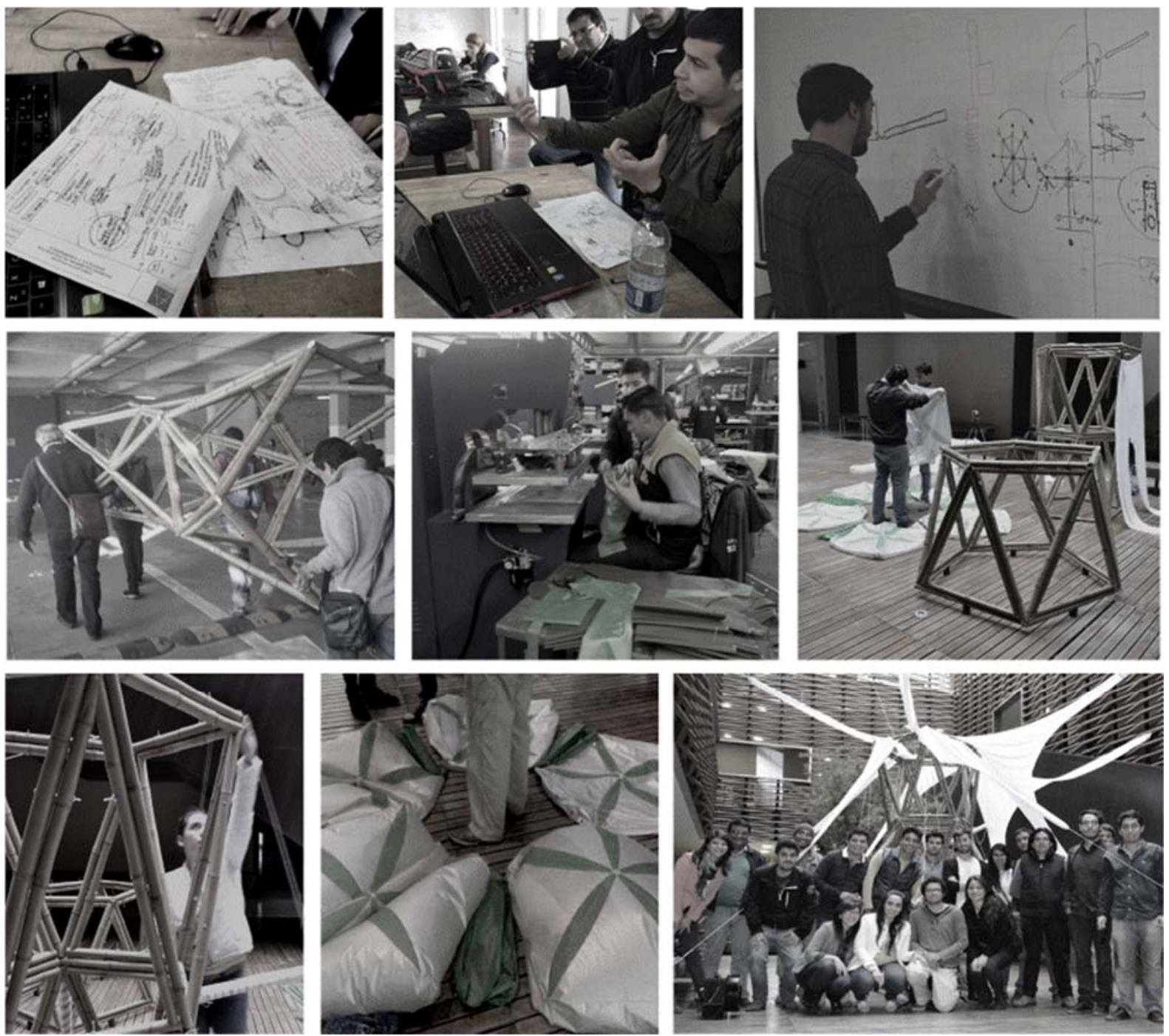
Figure 5: Development process of project 1 with collaborative learning at a distance

\section{Project 2: Exhibition stand}

This twelve-week project was based on the challenge of designing and building smallscale exhibition stands to be used for the end of the year shows at the University of Nottingham and the University of Los Andes. The project was carried out with a group of 56 undergraduate students (28 from the University of Nottingham and 28 from the University of Los Andes). The methodology included the same three pedagogies employed in Project 1 , with the difference that the formats were not used in a strictly defined order but overlapped between each other. For example, there was an active involvement of the 'client' and the industry from the beginning of the process. Hence, the live project format was central during a major part of the process. The other two formats were introduced at different stages and for particular purposes. For example, VDS was used to develop and evaluate conceptual ideas between both institutions, and conventional studio was periodically employed to assess progress and to guide the refinement of the proposals.

Figure 6: Development process of Project 2 with collaborative learning at a distance (University of Los Andes)

Figure 7: Development process of Project 2 with collaborative learning at a distance (University of Nottingham)

\section{Results}


Anonymous online surveys, focus groups and teachers' peer reviews were the main three tools used to gather data from the experiences. Photographs, videos and notes taken by the teachers and information submitted by the students were also used for the analysis. The online surveys comprised multiple choice and ordinal scale questions (e.g. very much, enough to be satisfied, more or less or not at all) designed to measure students' levels of motivation and engagement. The interviews for the focus groups included open ended questions formulated to evaluate students' perceptions of the overall experience compare to past studio projects and to assess collaborative work. For example, students were asked: What did you learn from the process of making the 1:1 scale prototype as a team, with budget constraints, compared to your individual studio project?. Guest teachers were invited at different stages during the projects and their reviews and comments were noted or recorded. For project 1 (with 25 postgraduate students), 22 online surveys were received, 3 focus groups ( 3 students each) were interviewed and 3 teachers were invited. For project 2 (with 56 undergraduate students), 48 online surveys were received, 4 focus groups ( 3 students each) were interviewed and 4 teachers were invited ( 2 in each country).

The online surveys (Figure 8) showed that higher levels of motivation and engagement were accomplished in Project 2 than in Project 1. Students from Project 2 appear more confident in regards to their own capabilities (self-efficacy) and personal achievements (self-regulation). In a similar vein, students appear to invest more effort on Project 2 (behavioural engagement) and go beyond the requirements (emotional engagement). In both projects, working with students from another institution appears to be the factor that inspired more situational interest and cognitive engagement, followed by working with the community and solving a real problem. This coincides with comments received by students during the focus groups (Figure 9). Students from Project 1 appeared to have higher levels of situational 
interest when working with students from another country, and lose self-motivation (selfefficacy) when this interaction stopped.

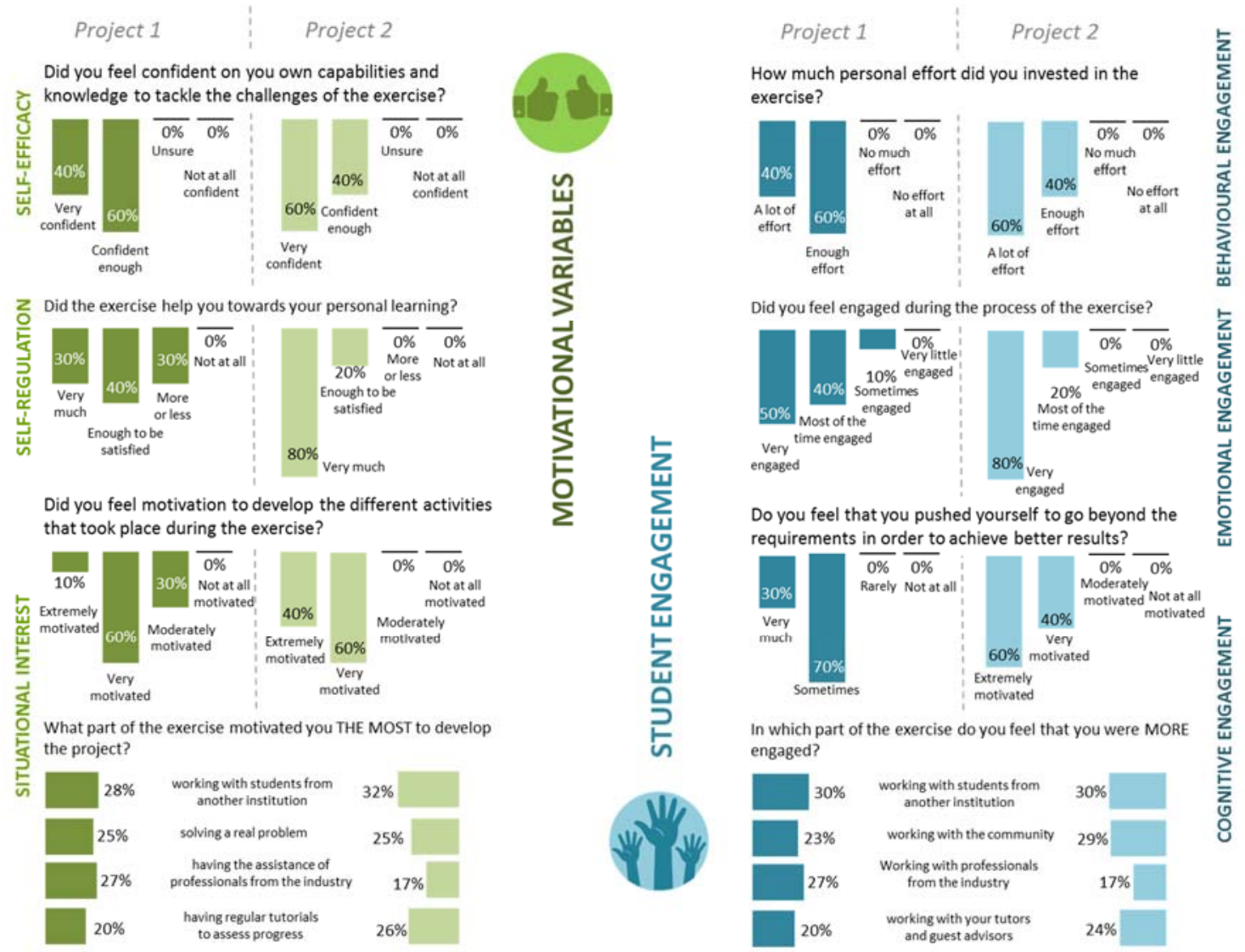

Figure 8: Results from the anonymous online survey for Project 1 and Project 2 


\section{Situational Interests}

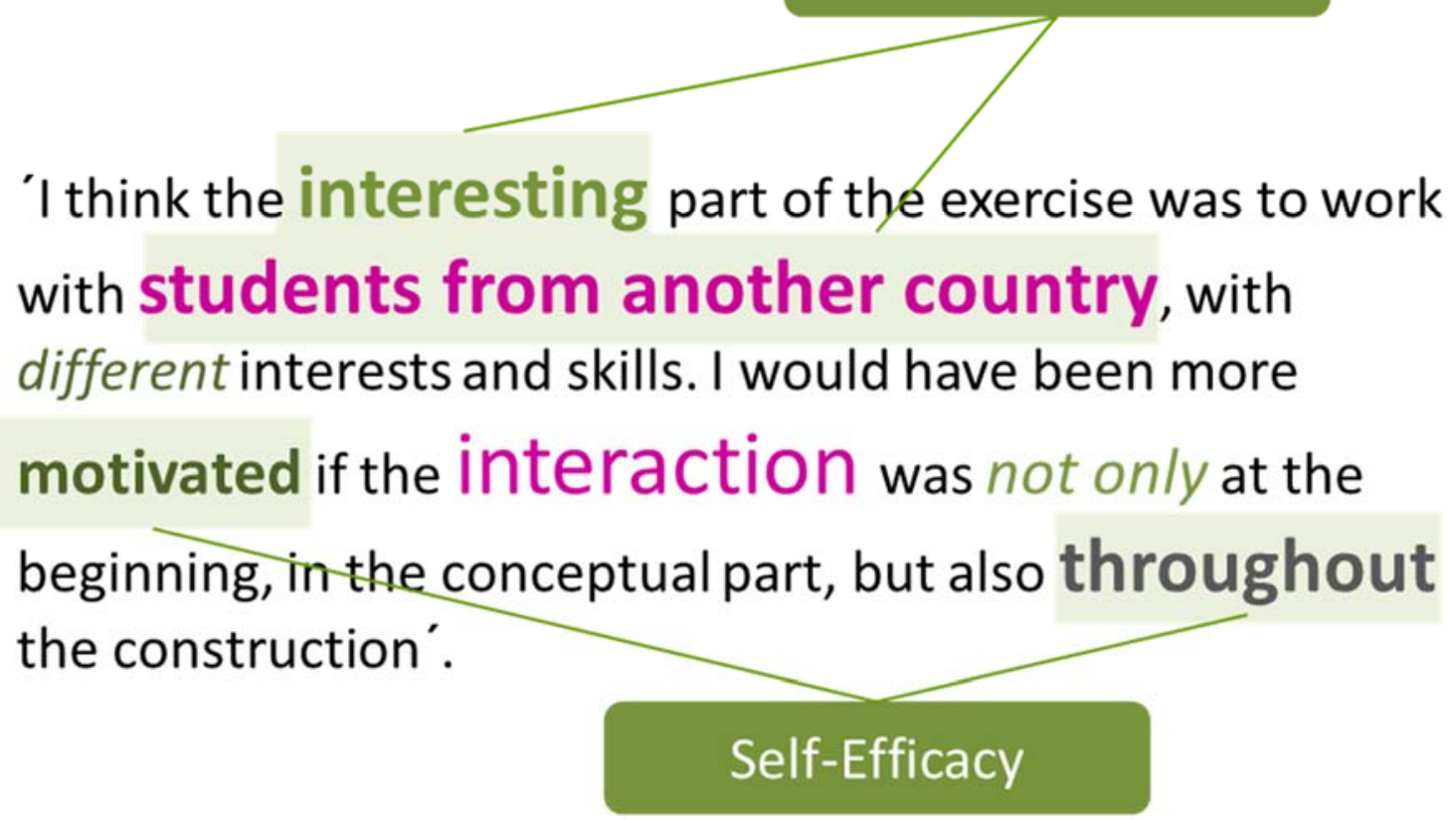

Figure 9: Comment by a student from University of Los Andes, Project 1 during focus group interview

For Project 2, ATLAS. ti was used as an additional tool to code all the collected information. Six codes were used to classify text (i.e. answers, comments, students' reports and notes) and visual information (i.e. photos, videos and audio recording), according to the types of engagement described by Fredricks (2005): self-efficacy, self-regulation, situational interest, behavioural engagement, emotional engagement and cognitive engagement. During this analysis it was also found that project 2 students seemed more convinced of the positive impact of the experience on their learning. They appeared to be more engaged and willing to work harder to achieve better results. This could be due to different reasons, for example, students from Project 2 were younger than students from Project 1 and, hence, had less experience of working within design projects, but demonstrated better skills working with ICT. The groups in Project 2 were more balanced, with the same amount of students from each country. In addition, the live projects in the second case study were more challenging since the industry and the community were more actively involved and the final project 
prototype was donated for later use. Various adjustments to the teaching approach were made to project 2, based on lessons learnt from project 1 (Figure 10). These were documented by the teachers during the course of the project and are thought to have helped improving collaboration between students, hence their application is suggested for future experiences applying a similar pedagogical approach. For each lesson learnt, noted in the left column, a suggested improvement is described in the column on the right.

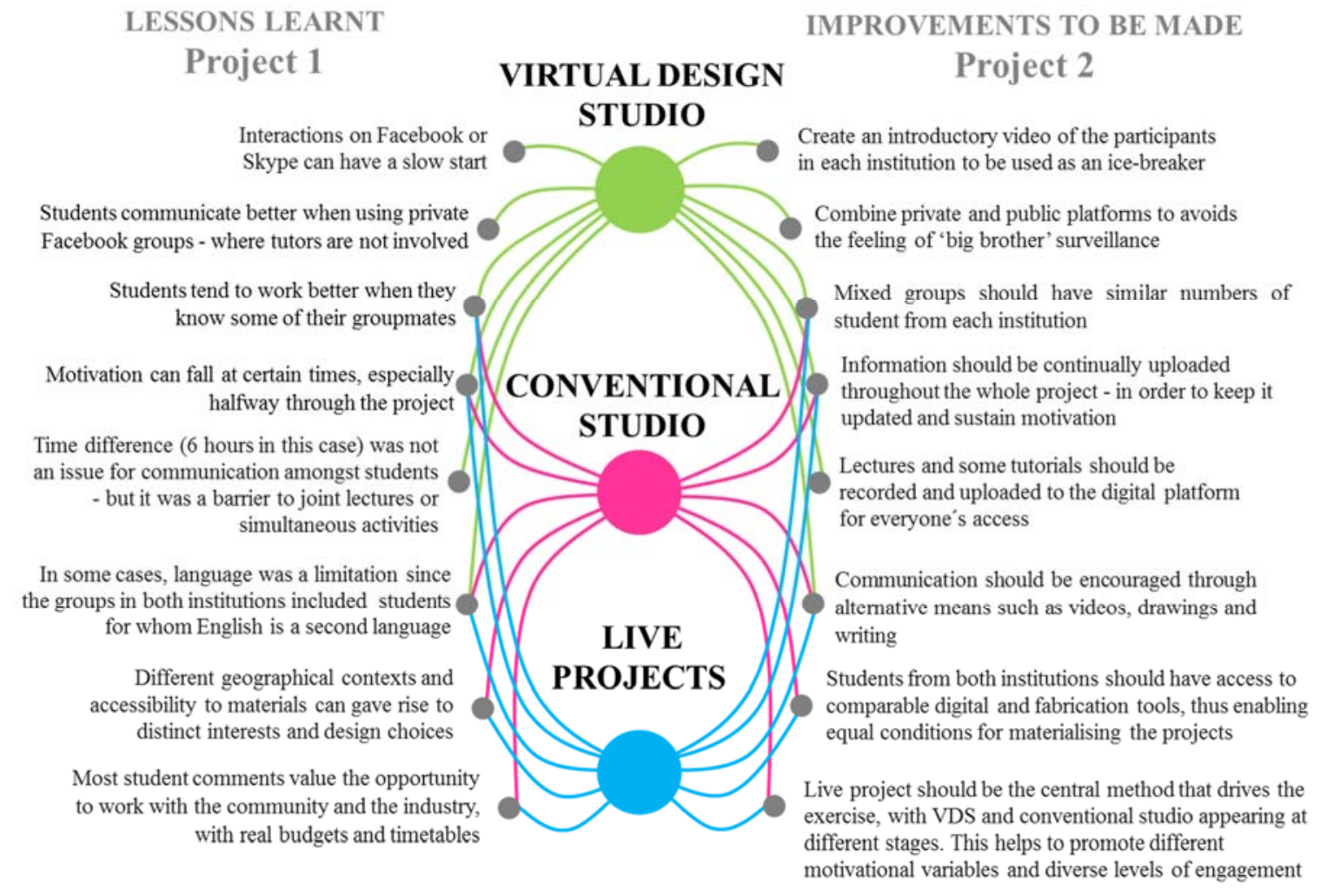

Figure 10: Lessons learnt and improvements to be made

It was observed in the focus groups' comments (Figure 11) that as Project 2 progressed students appear to be more independent, learnt to interact and collaborate better at a distance, and manage time and budgets more efficiently. Students seemed confident in their own abilities and motivated to tackle the projects. They reported that the experience was helpful for their personal learning and an improvement to the conventional studio format that they 
were used to. Teachers detected that WEB 2.0 tools were highly used by students to share digital files at the initial conceptual stage and before the final submission, during these periods students appeared to be mainly co-operating to build information. Collaborations and personal interactions progressively increased during the main central part of the project (decision making and materialisation stages) through chat forums, skype conversations and face-to-face meetings. These encounters involved negotiations, discussions, and accommodating the view of others, which coincides with Kvan's (2000) suggestion that better collaboration may be achieved when using these tools.

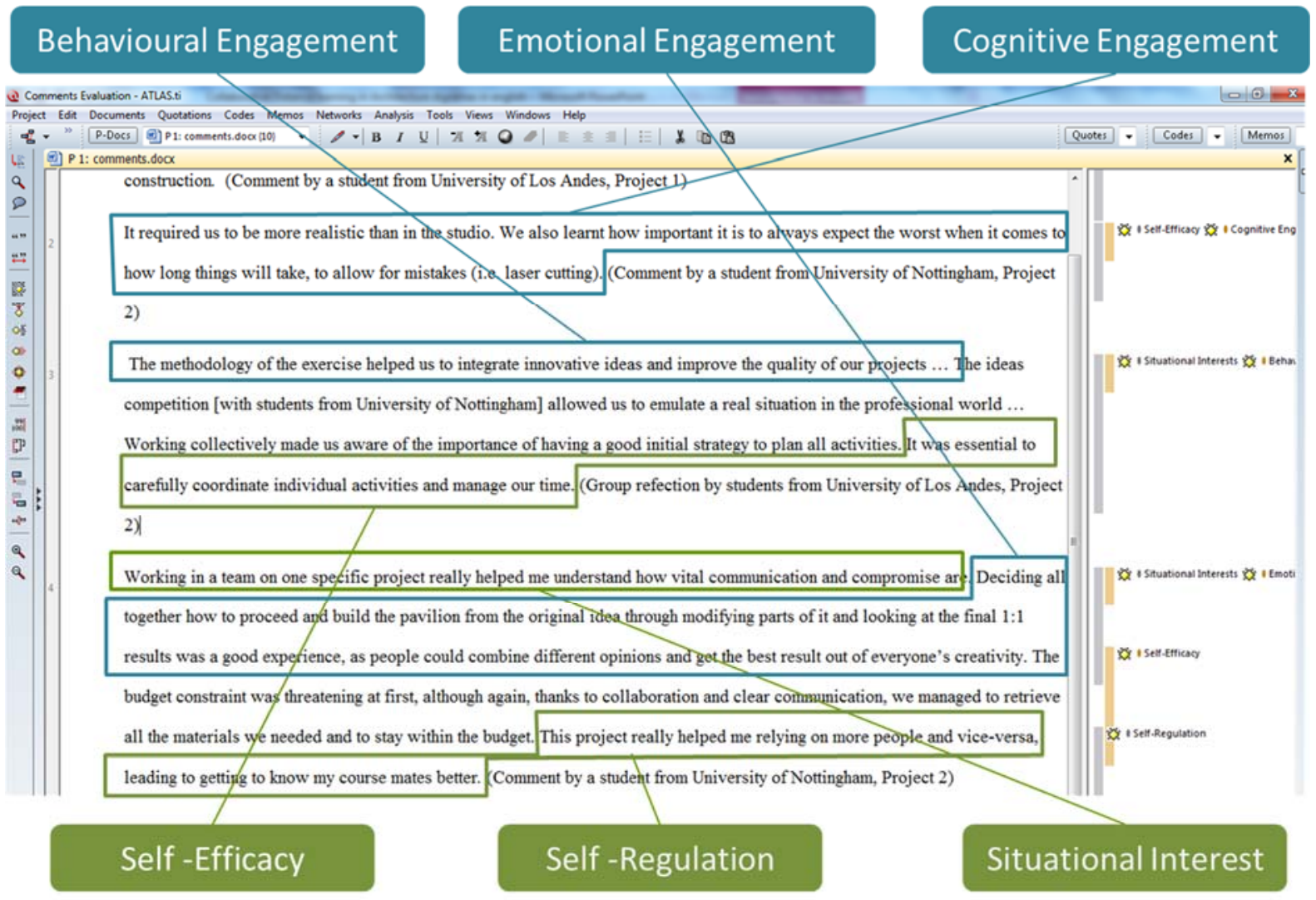

Figure 11: Evaluation of focus groups' comments using ATLAS.ti

\section{Conclusion}

The synergy between VDS, conventional studio and live projects proved to have considerable advantages and benefits over each pedagogy working separately, especially in 
Project 2 were the live project was central. The results validate the hypothesis posed by the study, since introducing aspects of a live project can help to overcome abstraction and detachment from reality, which have been found to be a problem in past experiences with VDS and conventional studio. In addition, collaborative work at a distance between students from different cultural backgrounds demonstrated to be a great motivation and to promote engagement. This evidenced that VDS can also add educational value to the conventional live project format. Compared to each format in isolation, the main benefits of the proposed combination have been identified as:

1. More student motivation and engagement is achieved when the academic project involves at the same time working with students from another institution, solving a real problem and working with members of the community outside the institution (e.g. clients or the industry).

2. Collaborative work is enhanced through a selection of means (e.g., virtually and face-to-face, using asynchronous and synchronous tools) acting in diverse settings (e.g. at a distance and on site).

3. The risk of favouring only certain types of learners is lower since students are exposed to the views of a variety of participants and not only their studio teacher.

4. Technical and practical constrains can be overcame having a range of possibilities for interaction.

The finding from this study provide new insights into traditional pedagogical models, which could result in adjustments to existing curricula. For example, in countries such Colombia, where professional practice or practical experiences before graduation are not a mandatory requirement for architecture students, the use of the proposed combination could 
be of great benefit. Projects similar to those presented here could be used within

undergraduate curricular programmes based on studio modules (normally 4-6 credits each).

\section{References}

Achten, H., Roelen, W., Boekholt, J-T., Turksma, A., \& Jessurun, J. (1999, September). Virtual Reality in the Design Studio: the Eindhoven Perspective. In A. Brown \& M. B. P. Knight (Eds.), Proceedings of the 17th eCAADe Conference: Architectural Computing from Turing to 2000 (pp.169-177). Liverpool, UK: University of Liverpool.

Achten, H., Koszewski, K., \& Martens, B. (2011, September).What Happened After the "Hype" on Virtual Design Studios?: Some Considerations for a Roundtable Discussion. In Tadeja Zupancic, T. (Ed.), Proceedings of the 29th eCAADe Conference: Respecting Fragile Places (pp.23-32). Ljubljana, Slovenia: University of Ljubljana, Faculty of Architecture.

Anderson, J., \& Priest, C. (2012, May). Developing a Live Projects Network and Flexible Methodology for Live Projects. Paper presented at Architecture 'Live Projects' Pedagogy, Oxford Brookes University, UK.

Bala, H. A., \& Arat, Y. (2012, November). Digital Pedagogy Using Social Network Tools in Architectural Education. Proceedings of 3rd World Conference on Information Technology (WCIT-2012) (pp. 160-166). Barcelona, Spain: University of Barcelona. Bridges, A. (2007, June). Problem-Based Learning in Architectural Education. Proceedings of CIB (International Council for Building) 24th W78 Conference (pp. 755-762). Maribo, Slovenia: Alborg University.

Dave, B. (1995). Towards Distributed Computer-Aided Design Environments. In M. Tan \& R. Teh (Eds.), Proceedings of the Sixth International Conference on Computer Aided Architectural Design Futures (CAADfutures): the Global Design Studio (pp.659-666). Singapore: Centre for Advanced Studies in Architecture, National University of Singapore.

Dooren, E., Boshuizen, E., \& Merriënboer, J. (2013). Making Explicit in Design Education: Generic Elements in the Design Process. International Journal of Technology and Design Education, 24(1), 53-71. doi:10.1007/s10798-013-9246-8.

Fredricks, J. (2005). School Engagement. In K. Anderson Moore \& L. H. Lippman (Eds.), What Do Children Need To Flourish? (pp. 305-321). New York: Springer. 
Gül, L. F., Williams, A. \& Gu, N. (2012). Constructivist Learning Theory in Virtual Design Studios. In Computational Design Methods and Technologies (pp. 139-162). Hershey: Information Science Reference.

Harris, H., \& Widder, L. (2014). Architecture Live Projects: Pedagogy into practice. Oxon: Routledge.

Harrison, D. \& Donn, M. (2006). Using Web 2.0 Technologies to Preserve Design History And Improve Collaboration. Proceedings of the 11th International Conference on Computer Aided Architectural Design Research in Asia, CAADRIA 2006: Rhythm and Harmony in Digital Space (pp. 111-117). Kumamoto: Kumamoto University, Japan.

Hou, J., Kinoshita, I., \& Ono, S. (2005). Design Collaborations in the Space Of CrossCultural Flows. Landscape Journal, 24(2), 125-139.

Jarrett, C. (2000). Social Practice: Design Education and Everyday Life. In D. Nicol, \& S. Pilling (Eds.), Changing Architectural Education: Towards a New Professionalis (pp. 49-59). London: Spoon Press.

Joklová, V. \& Henrich, P. (2015). Innovation in Architectural Education - OIKONET Experience. Global Journal of Engineering Education, 17(3), 124-131.

Kozar, O. (2010). Towards Better Group Work: Seeing the Difference between Cooperation and Collaboration. English Teaching Forum, 2, 16-23.

Krämer, B., Neugebauer, J., Magenheim, J., \& Huppertz, H. (2015). New ways of Learning: Comparing the Effectiveness of Interactive Online Media in Distance Education with the European Textbook Tradition. British Journal of Educational Technology, 46(5), 965-971. doi: 10.1111/bjet.12301.

Kvan, T. (2000). Collaborative Design: What is it? Automation in Construction, 9(4), 409415. doi:10.1016/S0926-5805(99)00025-4.

Livia, R. N. (2011). The Virtual Architectural Studio - An Experiment of Online Cooperation. Review of Applied Socio-Economic Research, 1(1), 38-46.

Lukman, N., Ibrahima, N., \& Utaberta, N. (2012). Learning in Architecture Design Studio. Procedia - Social and Behavioral Sciences. 60(2) 30-35. doi:10.1016/j.sbspro.2012.09.342.

Mallgrave, H.F. (2010). Architect's Brain: Neuroscience, Creativity and Architecture. Oxford: Wiley-Blackwell.

Maher, M. L., Simoff S. J., \& Cicognani A. (2000). Understanding Virtual Design Studios. London: Springer-Verlag. 
Meshur, H., Alkan, F. \& Bala, H.A. (2014). Distance Learning in Architecture/Planning Education: A Case Study in the Faculty of Architecture at Selcuk University. In P. Ordóñez, R.Tennyson, \& M. Lytras (Eds.), Assessing the Role of Mobile Technologies and Distance Learning in Higher Education (pp. 1-28). Hershey: IGI Global. doi: 10.4018/978-1-4666-7316-8.ch001.

Mitchell, W. J. (1995). The Future of the Virtual Design Studio. In J. Wojtowicz (Ed.), Virtual Design Studio (pp. 51-60). Hong Kong: Hong Kong University Press.

Ong Eu Ho, F., Janssen, P., \& Tian Ti, L. (2013). Group Forming: Negotiating Design via Web-based Interaction and Collaborationm. In R. Stouffs, P. Janssen, S. Roudavski \& B. Tunçer (Eds), Proceedings of the 18th International Conference on ComputerAided Architectural Design Research in Asia CAADRIA (pp. 271-280). Singapore: Open Systems.

Onyegiri, I., Nwachukwu, C.C., \& Jamike, O. (2011). Information and Communication Technology in the Construction Industry. American Journal of Scientific and Industrial Research. 2(3): 461-468. doi:10.5251/ajsir.2011.2.3.461.468

Salama, A. (2014, September). 'Liveness' Beyond Design Studio Pedagogy: Layers of 'Live' Within and Across the Boundaries of Classroom Settings. In Parnell, R., Rajendran, L.P. \& Mahdizadeh, S. (Eds.), Proceedings of the 2nd Annual AAE Conference 2014 Living and Learning (pp. 88-93). Sheffield: The University of Sheffield.

Sara, R. (2011). Learning from Life - Exploring the Potential of Live Projects in Higher Education. Journal for Education in the Built Environment, 6 (2), 8-25. doi: 10.11120/jebe.2011.06020008.

Schnabel, M. A. (2011). The Immersive Virtual Environment Design Studio. In X. Wang, \& J. H. Tsai (Eds.), Collaborative Design in Virtual Environments. Series Intelligent Systems, Control and Automation: Science and Engineering, 48 (pp. 177-191). London: Springer.

Schnabel, M. A. \& Ham, J. (2012). Virtual Design Studio within a Social Network. Journal of Information Technology in Construction (ITcon), 17, 397-415. Available at: http://www.itcon.org/2012/27.

Singh, V., \& Wang, N. (2011). A theoretical framework of a BIM-based multi-diciplinary collaboration platform. Automation in Construction, 20 (2), 134-144. doi:10.1016/j.autcon.2010.09.011.

Sun, J. C.-Y. \& Rueda, R. (2012). Situational Interest, Computer Self-Efficacy and SelfRegulation: Their Impact on Student Engagement in Distance Education. British 
Journal of Educational Technology, 43: 191-204. doi: 10.1111/j.14678535.2010.01157.x.

Tuckman, B. (2007). The Effect of Motivational Scaffolding on Procrastinators' Distance Learning Outcomes. Computers \& Education, 49(2), 414-422. doi:10.1016/j.compedu.2005.10.002.

Wang, J. (2012). Challenging ICT Applications in Architecture, Engineering, and Industrial Design Education. Hershey: IGI Global. 